\title{
PERSPECTIVES ON INNOVATION: THE ROLE OF ENGINEERING DESIGN
}

\author{
Isaksson, Ola (1); Eckert, Claudia (2); Borgue, Olivia (1); Hallstedt, Sophie I (3); Hein, Andreas \\ Makoto (4); Gericke, Killian (5); Panarotto, Massimo (1); Reich, Yoram (6); Öhrwall Rönnbäck, \\ Anna B (7)
}

1: Chalmers University of Technology; 2: The Open University; 3: Blekinge Institute of Technology; 4: Université Paris-Saclay; 5: University of Luxembourg; 6: Tel Aviv University; 7: Luleå University of Technology

\begin{abstract}
The aim of the paper is to foster a discussion in the engineering design community about its understanding of the innovation phenomena and the unique contribution that comes from engineering design. The paper reports on the dialouge originating from a series of workshops with participants from different backgrounds in engineering design, systems engineering, industrial design psychology and business.

Definitions of innovation are revisited as used in business, management and engineering design contexts. The role of innovation is then discussed related to product development from (i) the management perspective, (ii) a systems architecture perspective and (iii) in relation to sustainable development as one driver of innovation.

It is argued that engineering design has a central role in how to realise the novelty aspect of innovation and often plays a critical role in maturing these into the valuable products, and there is a need to articulate the role of engineering design in innovation to better resonate with the business and management research.
\end{abstract}

Keywords: Innovation, Design engineering, Design process, Design management

Contact:

Isaksson, Ola

Chalmers University of Technology

Product and Production Development

Sweden

ola.isaksson@chalmers.se

Cite this article: Isaksson, O., Eckert, C., Borgue, O., Hallstedt, S.I., Hein, A.M., Gericke, K., Panarotto, M., Reich, Y., Öhrwall Rönnbäck, A.B. (2019) 'Perspectives on Innovation: The Role of Engineering Design', in Proceedings of the 22nd International Conference on Engineering Design (ICED19), Delft, The Netherlands, 5-8 August 2019. DOI:10.1017/dsi.2019.129 


\section{INTRODUCTION}

To be successful with innovation is key for companies and necessary both to meet new and existing needs. Ideas and innovations can also generate needs, requirements and desires that have not been previously recognised and thereby open up new markets and builds up brand reputation if developed into implemented innovations. The term innovation is used widely but not always clearly defined in both the engineering design and the business research communities. Therefore, it can be difficult to distinguish how research contributions from domains such as these two build on each other. The aim of the paper is to foster a discussion in the engineering design community about its understanding of the innovation phenomena and the unique contribution that come from engineering design. A guiding research question is stated as "How does the engineering design literature contribute to our understanding of innovation?"

A survey commissioned by the European Union (2014) showed that 3 in 10 companies did introduce innovation on the market. $79 \%$ of companies that introduced at least one innovation since 2011 experienced an increase of their turnover by more than $25 \%$ by 2014 . Innovations that companies are most likely to have introduced new or significantly improved services $(38 \%)$ or goods $(37 \%)$. One third have introduced new or significantly improved marketing strategies $(33 \%)$, while $30 \%$ have introduced new or improved organisational structures and 29\% new or improved processes This classification (Freeman, 1991) implies that a large range of changes of improvements may be seen as an innovation. The business school community is often taking this view, and talks about any kind of the new product or service as an innovation. The European Union also sees design as an important means to innovation in its policy ${ }^{1}$. Designers and engineers also generate new solutions, many of which they themselves would not consider to be innovations, because they use existing solution principles and well established processes to create them. For example the first bagless vacuum cleaner was widely talked about as an innovation in vacuum cleaner technology. The annual update of a standard vacuum cleaner would not be considered an innovation by the design department but might be marketed as an innovation by the business part of the firm. Market introduction alone is not an innovation, as the GoPro camera for action sport illustrates exemplifies. GoPro is engineered based on established design solutions but repurposed them successfully for new users and market segments.

If all new solutions are considered innovation, the focus on innovations that make a difference is lost. It trivialises both design and innovations and hides the importance of design and the transformative power of innovations. We take the view that innovation should be novel and be successfully introduced on the market (Kaiserfledt, 2006; OECD, 1991). Hence invention may not necessarily be an innovation (Kaiserfledt, 2006; Freeman, 1991) since only the novelty criteria can be satisfied. However, what constitutes novel and what is successfully introduced is a matter of debate and interpretation. As an example, open rotor technology for aircraft propulsion has been flight tested as a new concept in 1986, but was not carried forward to market introduction at the time (Butterworth-Hayes, 2010). The same idea is now reintroduced as a potential innovation and undergoes an ambitious test program in Europe. Hence, the open rotor is an invention but not yet an innovation. The effort of turning invention into a successful innovation requires in this case substantial engineering effort and advancements in product development. Similarly, the business department may take a different view on this, focusing on the potential of the technology and the readiness to complete it fully.

This paper is a collective effort by members of the Modelling and Management Engineering Processes (MMEP) special interest group (SIG) of the Design Society, who share a passion in understanding and supporting engineering design practise. The overall structure of the paper emerged from the MMEP workshop at DESIGN18. One result from the workshop was the need to articulate what role ED has in the Innovation landscape. This paper is not a review paper, but rather as a first report so that we can collectively built on it and start a discussion in the community about our view of innovation.

The paper brings together key definitions of innovation in section 3 and discusses the role innovation and innovation management can play in the product development process in sections 4 and 5. As many of the key decisions about where and how to innovate in a product are made early in the product development process, section 6 looks specifically at innovation in the context of system architecture

\footnotetext{
${ }^{1}$ https://ec.europa.eu/growth/industry/innovation/policy/design_en
} 
design. Innovation is often driven by the need to improve particular aspects of a product. There are many drivers for innovation, which have motivated communities to address innovation. Section 7 looks specifically at design for sustainability, where it has been recognised a long time ago that significant innovation will be required to make products more sustainable.

\section{CONTEXT AND METHODOLOGY}

This paper summarises the results of a series of workshops organised by the MMEP SIG. Three workshops with the shared theme "organising innovation" were organised between September 2017 and May 2018. The participants had different backgrounds such as engineering design, systems engineering, industrial design psychology and business.

56 experts participated in the first workshop, which was organised during the ICED' 17 conference in Vancouver. Five invited talks triggered the subsequent discussion, which unveiled gaps in understanding and the heterogeneity of views that the participants had. It became clear that additional aspects and viewpoints need to be considered and that the meaning of innovation lacks clarity.

Triggered by these results a second workshop with the same theme was organised in February 2018 in Paris at Centrale Supélec, with 15 researchers participating. Based on six invited talks and results of the previous workshop the group created an affinity diagram to organise identified topics and results of the discussions. One of the goals of this workshop was to converge from the broad range of topics addressed in Vancouver to a set of core topics that are essential to link the broad range of related viewpoints.

The last workshop during DESIGN'18 in May 2018 was intended to integrate all insights from the previous workshops. During this workshop the group of authors of this paper formed and defined the issues to be addressed, the structure of the paper and areas that require further research.

The discussions that span across the three workshops were highly iterative. A core team of participants that attended all workshops continued their exchange and organised the convergence of the discussions in between the workshops via telephone and e-mail. While the first workshop provided a broad overview of related viewpoints on the addressed subject, the subsequent workshops and communications were aimed to focus on the central aspects that we believe are relevant to provide a basis to integrate the many different viewpoints of the different communities that share the same interest in innovation.

In an effort to clarify the relation of innovation management and product development, the definitions and different notions of its understanding in these disciplines have been further investigated performing a literature study involving researchers representing both fields. Moreover, literature that takes a multidisciplinary and interdisciplinary perspective, i.e., that tries to identify the common elements of innovation across disciplines, has been included in this study.

\section{DEFINITIONS}

Innovation is central to product development. However, depending on the discipline, the life-cycle phase and the role of a person, the term innovation is understood and used in a subtly different way (e.g. between business and engineering fields, Schilling 2017). Different communities claim ownership of the term. Based on a content analysis of 60 definitions of innovation from business and management, economics, organisation studies, innovation and entrepreneurship, and technology, science and engineering. Baregheh et al. (2009) offers an interdisciplinary definition of "innovation as a multi-stage process whereby organizations transform ideas into new/improved products, service or processes, in order to advance, compete and differentiate themselves successfully in their marketplace".

Most definitions of the term innovation relate back to Schumpeter's (1947) theory of innovation. Schumpeter used the term initially as "By innovations I understand ... changes of the combinations of the factors of production ... They consist primarily in changes in methods of production and transportation, or in changes in industrial organization, or in the production of a new article, or in the opening up of new markets or of new sources of material (Schumpeter, 1927)." Later he moves beyond the recombination of elements and refers to innovation as: "the doing of new things or the doing of things that are already done, in a new way (Schumpeter, 1947)."

Newness is a key concept in innovation. The management literature offers a brief definition of innovation as "a new match between a need and a solution" (Terwiesch and Ulrich, 2009). By analysing what innovative means, Cooper (2011) defines "newness" of products along two axes: "new 
to the company" and "new to the market." Based on that, he distinguishes six different types of new products: New-to-the world products, new product lines, additions to existing product lines, improvements and revisions to existing products, repositioning, cost reductions.

In engineering design Pahl and Beitz (2007) define innovation as follows "An innovation is a product that realises new functions and properties. This could be through novel or new combinations of existing solutions." They distinguish between innovation and invention. "An invention is something truly new and is often based on the application of the latest scientific knowledge and insights (Pahl and Beitz, 2007)." Innovation and inventions are closely related to original design, which they define as: "New tasks and problems are solved using new or novel combinations of known solution principles." The combination of novelty and market introduction is else highlighted by Papalambros (2008) who sees innovation as "'the introduction of something new', 'a new idea, method or device', 'the successful exploitation of new ideas'.

There is a general consensus in all these definitions that innovation is related to something being new. The difference lies in the degree of newness and what is new. Pahl and Beitz (2007) suggest that innovation implies new functions or properties to the product, rather than being improvements or changes to existing ones, whereas the innovation management definitions focus on the effect of innovation and include changes to existing products as long as they add value or are successful in the market (Schilling 2017).

Engineering companies tend to approach newness from the perspective of how much they know about the component or system and argue that a component or system is new either, if it is newly designed or deployed in a new or different context, e.g. under a different operational temperature. In the design of mature products companies set targets to minimise newness for e.g. number of components or systems that are carried over from previous products or platforms (Wyatt et al., 2009). In engineering newness is associated with risk, as a new system has not been tried in practise or in a different context and the technology it is built upon is not yet validated, e.g. (Hein, 2016). The aerospace industry (Mankins 1995) has developed technology readiness levels (TRL) to assess whether a technology is sufficiently mature to be deployed in a product, where TRL 1 corresponds to a new basic principle that is discovered, TRL 5 requires a test in a realistic product and TRL 9 is required for introduction in a product. If tying innovation to market success, innovation would then only occur when TRL 9 is met and the product enters the market. If innovation is tied to newness only, innovation would happen at earlier TRL stages.

Both communities seem to agree that innovation involves and requires elements of newness and successful market introduction, however the degree of newness and market success required to constitute innovation and the balance between the two is a matter of interpretation. All in all, the above discussion shows that the concept of innovation differs and is contextual. Different bodies of literature focus on particular aspects of innovation. Both product development (PD) and business research (often referring to innovation management) focusses on the process of creating innovative products, however PD puts more emphasis on the technical realisation and innovation management more on the management and business success aspects. In short, the engineering design research view on innovation is more on the novelty of product content and function, whereas business and management fields of research on innovation focus more on the effect of products and its relations to markets and actors engaged.

\section{INNOVATION IN PRODUCT DEVELOPMENT}

PD for complex mechanically dominated products are often organised in a PD process, where the decision control logic is one view (Cooper, 1988) and the design logic is the other. Currently, manufacturers of complex products, such as automotive and aerospace, seek more flexible development processes to allow for a higher degree of customisation while still retaining commonality and platforms (Avner et al, 2017).

Product development can be straight forward and comprise little degree of novelty or risk, yet still comprise a significant amount of work to prepare. In relation to innovation, PD can be used to deliberately seek to realise new ideas or meeting new needs on a market. The PD organisations know upfront that there is a novelty expected as an outcome. A more subtle condition is the case where a PD team runs into challenges that were not foreseen, and novel strategies need to be adopted to resolve the 
issues. In practice, this is frequently occurring and we can refer this to accidental innovation. Sources of innovation in PD are unpredictable and can be multiple (von Hippel 1988, 2005).

This is closely related to the notion of radical vs incremental innovation, where incremental innovation relies on the confidence that the product to be designed is similar to a precedent design. Radical innovation indicates that there is a bigger risk, and a major effort expected to realise the idea or develop solutions to a need, as new engineering and physical principles might be used (Henderson and Clark, 1990).

The results of the $R \& D$ programs or pre-studies are usually introduced into product ranges in a structured way according to technology roadmaps or product plans. Technology roadmapping has originally been developed to integrate product technology strategy and product planning (e.g. Groenveld, 1997) for specific companies and has later been applied to entire industry sectors to inform policy development (Kostoff \& Schaller, 2001). The approach is now widely applied and can be customised to different settings (Phaal et al., 2004). These plans lay out at which point a technology needs to be ready to be introduced into a product or product family and can therefore be used to drive the creation of innovation as well as the maturing of innovative technologies to get them ready for introduction into industry.

From a technology-centric perspective, Zelkowitz (1996) distinguishes between technology transfer, where new technology, which is for example developed by a university, is transferred to an entire industry sector and technology infusion where a new technology is introduced into a specific product. For a company one of the challenges is the selection of promising technologies not just on the merit of the technology itself, but also the implication this introduction has for the product (Smaling and de Weck, 2007), as this process can be associated with considerable cost (Suh et al., 2010). It is rarely possible to contain a new technology to a single system without considerable change propagation and thereby costly impact on other systems.

The idea of technology introduction is a deliberate strategy to bring innovation into a product, however innovation can also be introduced into products as a mitigation for problems that emerge as part of the product development process (Schilling 2017). As the product development process progresses the design becomes more and more constrained by the decisions that are already fixed and the shortening time scale, which makes companies look for solutions that change little in the overall design, even if they bring in newness (Eckert et al., 2012). The tensions between organized and controlled innovation work, e.g. systems engineering for critical components and systems, and the innovative and creative work that fosters unpredicted innovation, can be a delicate balance for corporate management and engineering leadership. This tension can partly be explained by the tension between cost and profit, always prevalent in the business context; to be able to cover costs for innovation work, and bear the risk of failure. At the end of the day, companies need to get return on their investment in innovation and engineering efforts at early stages. "A large part of the value of an innovation is determined by the degree to which people can understand it, access it, and integrate it..." (Schilling 2017:291) Innovation is not only generating revenues, but "deployment is a core part of the innovation process itself" (ibid).

To summarize, PD in terms of realizing innovations creates tension between induced cost, risk of introducing newness and the future profit that would potentially be generated. Therefore the PD literature tend to see innovation as something driven by need to meet expectations and requirements, whereas the business and management community rather regard, innovation as a positive characteristic of organisations acting proactively with their product strategy.

\section{MANAGING INNOVATION IN PRODUCT DEVELOPMENT}

The business and management literature focusses on assuring that the effect of innovation can be realised. Well-executed innovation management is decisive for competitive success (Adams et al., 2006) and understanding how to perform innovation is a key success factor (Oliveira et al., 2017). In this sense, the innovation is seen as more strategic, emphasising strategic investments in renewing product and technology over time and in all phases of the PD process. Innovation strategy needs to be consistent with the overall company strategy, production capacity, market strength, technological capabilities and costa (Oliveira et al., 2017). For innovation to be successful it must be carefully aligned with the PD process and managed in a holistic way through the whole PD process (Chaochotechuang et al., 2015; Sundbo, 1997). 
Successful innovation management depends on multiple factors. Cooper et al. (1999) advises to focus on making strategic, technological and resource choices related to project selection. However, areas related with resourcing of innovation activities, including activities such as finances or HR, are also considered vital (Adams et al., 2006). These resource-based areas together with access to finance, highly skilled workforce and engaged management drive innovation (Goedhuys and Veugelers, 2012; Chaochotechuang et al., 2015).

From a strategic leadership perspective, the behaviour of senior management is highly influential in innovation management success (Dougherty and Cohen, 1995). Executives most likely to make innovation successful are those with a clear vision of the future and that support organizational and cultural change, fostering company strategy evolution (Sundbo, 1997).

Another strategy companies can apply to enhance product innovation is to engage in networking with for instance, manufacturers, other companies or clients, to increase market information and technological capabilities (Serra and García, 2013; Hansen and Birkinshaw, 2007). This way, the firm can have access to valuable market information that enables it to target innovation initiatives, without wasting valuable resources and time learning through trial and error (Serra and García, 2013; von Hippel 1986; Goedhuys and Veugelers, 2012). Finally, for the product launch and implementation stage it is companies' marketing capabilities that are significant (Calantone and di Benedetto, 1988).

To summarize, business innovation management literature concludes that for companies to thrive the product development process is not an end to itself but needs to be aligned with company strategy, technological capabilities, cost, etc. and relies on success factors such as a clear vision of senior management for making the necessary changes. While innovation needs to be actively managed through the PD process, many of the fundamental decisions about innovation in a product are set with the system architecture.

\section{INNOVATION AND SYSTEM ARCHITECTURE}

In this section, we are shifting the focus to the product's architecture, when key decisions are made. The relationship between product and system architecture and innovation has received considerable attention in the strategic management, technology management, product development, and system architecture literature. Nevertheless, their focus differs considerably.

The product architecture has been an important topic in the strategic and technology management literature, where innovation has been categorized in terms of modular, architectural, and radical innovation in Henderson and Clarke's seminal publication on architectural innovation from the management literature (Henderson and Clark, 1990). Modular innovation remains on the component level, whereas architectural innovation changes the relationships between components, and radical innovation impacts both the components and relationships. Furthermore, radical innovation is commonly based on new engineering and physical principles and may have the potential of opening up new markets (Henderson and Clark, 1990). They argue that innovation of the product architecture could challenge incumbent companies, as the change in architecture (relationships between components) induces changes to a company's organization. Notably, the Design Structure Matrix literature has addressed this issue from a management and engineering design point of view (Sosa et al., 2011; Sosa et al., 2004). The reverse, called "mirroring hypothesis", where the product architecture reflects the architecture of the organization developing the product (Colfer and Baldwin, 2016; Conway, 1968; MacCormack et al., 2011) is often seen as a barrier to innovation.

Baldwin \& Clark (2000) have explored in-depth the relationship between the dynamics of innovation in the microcomputer industry and the product architecture of microcomputers. Notably, the emergence of modules and design rules for interfacing the modules accelerates the introduction of innovations on module level. Research on dominant design (Anderson and Tushman, 1990; Tushman and Anderson, 1986) has looked into the relationship between the development of industries and its dependence on a stable product architecture.

The product architecture and systems architecture literature has mostly focused on this relationship with an emphasis on the product itself (Crawley et al, 2015). For example, the literature on technology infusion proposes approaches for managing the introduction of component innovations into an existing product architecture and the effect this introduction would have on the architecture (Smaling \& de Weck, 2007; Suh et al, 2010), as previously mentioned in Section 4. More recently, the introduction of new technologies to a wider organizational and system of systems ecosystem has been explored (Hein et al, 2018). 
To summarize, the strategic and technology management literature attend more to the relationship between types of innovations in a product and its effect on an industry and vice versa. The product and systems architecture literature in engineering design on the other hand, focusses on the effects of introducing technology and innovations to the product architecture itself. Generally, innovation is often driven by a desire to address specific needs, behaviours and other aspects associated with a product, without impairing the core functionality of the system architecture. One such aspect is sustainability.

\section{INNOVATION FOR SUSTAINABILITY}

Sustainability is an important driver for innovation and the life cycle perspective opens up new opportunities for innovation. For example, within the aeronautic industry the Advisory Council for Aeronautics Research in Europe (ACARE) has set up some high-level targets such as the "Ultra green air transport system". Concrete targets on product functionality such as lighter weight, noise reduction, emission reduction and high reliability are prioritized parameters in concept selection. Also new fuels, totally new designs to reduce fuel burn, and new flight routes are concrete measures for reduction of the environmental impact from airplanes in operation (ACARE, 2011).

When full life-cycle responsibility is added, not only from an environmental but also from a social perspective, and from material extraction, via production and use, to component scrapping, the complexity increases even more. There is a challenge in being able to optimize these aspects and at the same time being competitive in the market. Using sustainability as a driver for innovations can open up new possibilities and ways to be competitive at the future market.

To implement sustainability in the early stages of the product innovation process means that it provides opportunities for improving sustainability aspects of a product and for enhancing the product competitiveness (Chiu and Chu, 2012). Achieving a sustainable solution requires a life cycle perspective and fundamental changes to production and consumption systems that goes well beyond resource efficiency and recycling waste in order to meet the requirements in the transition towards a circular economy (EEA, 2017). To preserve the value of products for as long as possible plays a central role and puts products centre-stage in the transition process. This means life cycle implications and solutions are needed rather than just innovation of a product and its features "only".

Increased capabilities to integrate sustainability aspects in the early design stages is therefore very important for the future of the company (Schulte and Hallstedt, 2017) and in order to create sustainable innovations. The engineers need to know which and how method and support systems for sustainability integration are used, and which and how sustainability-related decisions are taken during the product innovation process. The self-benefit for the company is then clear through, for example, new innovations that provide more customer value, the attraction and maintaining of top talent employees, a strong brand and business image, being ahead of legislation, more motivated and loyal employees, lower operating and credit costs, lower vulnerability to sudden market changes (Testa and Iraldo, 2010; Willard, 2012). In short, engaging in increased capabilities for sustainable product development is a way to exploit business opportunities and avoid long-term negative consequences, which means that it is smart risk management (Schulte and Hallstedt, 2018). Sustainability is a good example that simultaneously brings principally new perspectives on both business, management and development of innovation.

\section{REFLECTION}

Newness and improvement of products are important as an integral part of engineering design. In the engineering design community, innovation implies a change or newness that goes beyond standard and incremental design, something that is challenging or disruptive, a new solution principle. This means, a new technology or a new way of working that the organisation is unfamiliar with, and which implies a certain degree of risk to the organisation. A product which is only a version of an existing one would not be seen as an innovation but as regular product development activities. By contrast, from a business perspective the effect of introducing a known, or incrementally improved, product to a new market can be seen an innovation, because it is new in the sense of not having existed in the past. Depending on the innovation taxonomy in the business literature, innovation in the engineering design sense can be radical (discontinuity in product and market), really new (discontinuity in product) (Garcia and Calantone, 2002). However, a discontinuity in market (a specific form of really new 
innovation according to Garcia and Calantone (2002)), where the product essentially stays the same, would not be considered an innovation from an engineering design perspective. In both cases innovation requires a successful implementation and value creation.

Figure 1 shows "novelty" and "successful market introduction" as two axes and the degree of innovation as contour lines. It illustrates that products are somewhere in a spectrum of market introduction and novelty and positioned in the top right corner (3) in Figure 1 satisfies both criteria on innovation. However, where the line is drawn between routine development and innovation is a matter of interpretation of how the innovation is realised. While novel applications of known technology ( 2 in Figure 1) can be regarded as a business innovation, e.g. the GoPro camera, novel technologies and applications can be seen as a technology innovation with little or no market success (4 in Figure 1). Product development plays an important role to understand the feasibility, risk and effort necessary to deliver novelty successfully to a market (3 in Figure 1).

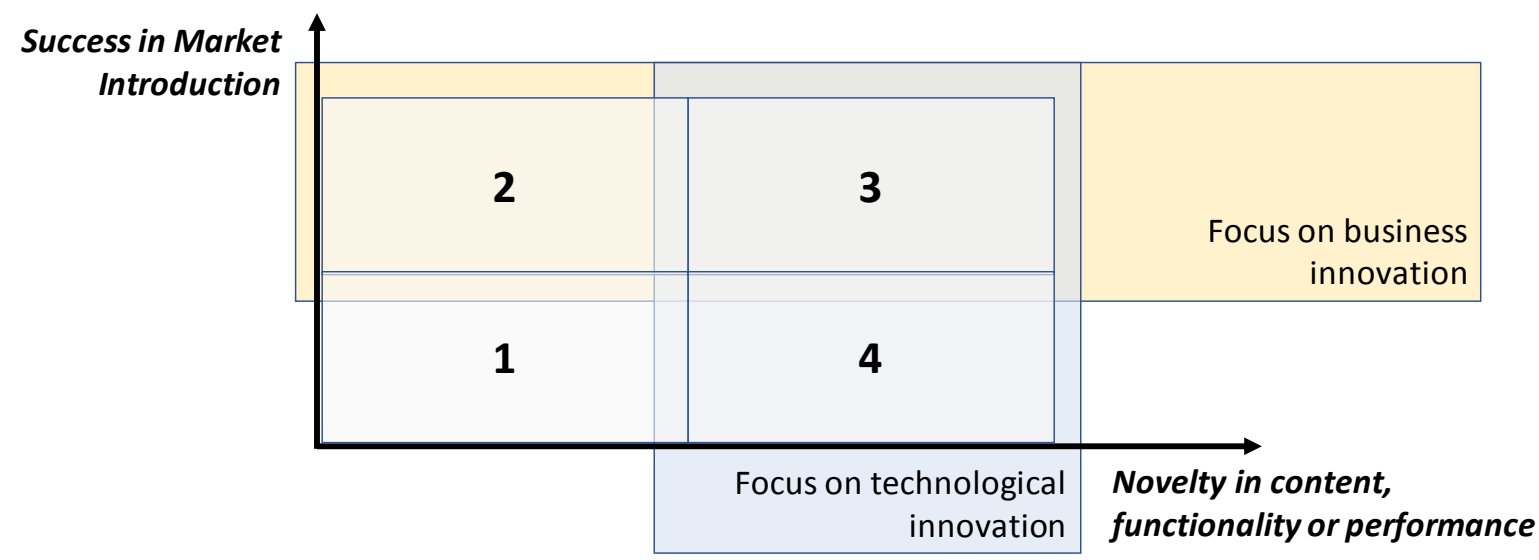

Figure 1. Spectrum of market introduction and novelty. The design and business viewpoints agree on that the top right corner constitutes innovation.

Defining innovation by novelty $(3,4)$ and successful market introduction $(2,3)$ is necessary but not sufficient from an engineering design point of view, since it does not consider how the innovation has been realized. Classically, a change in the way innovation is realized would be a form of process innovation (Utterback and Abernathy, 1975). The design view includes how the innovation is realized. An innovation would require novel technologies and/or new design rules and principles. Unless we know how to realize the innovation, we are likely to fail. As the example of additive manufacturing illustrates, the new way of producing things requires considerable knowledge and effort to successfully realize innovation. Unless design skills and processes are available and used, ideas and inventions do not become innovations. From a design perspective, the GoPro camera example does not qualify as an technology innovation, but rather a successful product development, but possibly a business innovation. From a business perspective, innovation points to the potential of new sales and revenue. Therefore innovation is seen as something positive and innovation becomes part of the rhetoric of the business community. In engineering, innovation points to the risk. The rhetoric of engineering is therefore often pointing to limiting the risk of innovations that often are "new features" of types of products already existing for which the customers, users or public can see a benefit, but down played for other parts of the system.

Innovation is a priori a common concept, which can bring both benefit as well as costs and risks. However, the discourse on different innovation perspectives risks hiding the benefits and challenges associated and makes the collaboration across disciplinary boundaries difficult. This paper has drawn attention to the multiplicity of viewpoints and communities that address innovation and has highlighted the need to be explicit about what is meant by innovation. Since both "novelty" and "successful introduction" are difficult to measure objectively and across products, innovation alone is subject to interpretation. From an engineering perspective, exploring novel technologies using new means to realise them to develop new products are fundamental for product development for innovation. 


\section{REFERENCES}

Adams, R., Bessant, J. and Phelps, R. (2006), “Innovation management measurement: A review”, International Journal of Management Reviews, Vol. 8 No. 1, pp. 21-47. Available at: http://dx.doi.org/10.1111/j.14682370.2006.00119.x

ACARE (2011), "Fligthpath 2050 - Europe's Vision for Aviation”, Report of the High Level Group on Aviation Research. Advisory Council for Aeronautics Research in Europe, October 2004. Publications Office of the European Union. ISBN 978-92-79-19724-6

Anderson, P. and Tushman, M. (1990), "Technological discontinuities and dominant designs: A cyclical model of technological change", Adm. Sci. $Q$.

Baldwin, C.Y. and Clark, K.B. (2000), "Design rules: The power of modularity", MIT press.

Baregheh, A., Rowley, J. and Sambrook, S. (2009), "Towards a multidisciplinary definition of innovation", Manag. Decis. Vol. 47, pp. 1323-1339. https://doi.org/10.1108/00251740910984578

Butterworth-Hayes, P. (2010), "Open Rotor research revs up", Aerospace America, March 2010

Calantone, R.J. and di Benedetto, C.A. (1988), “An integrative model of the new product development process: an empirical validation”, Journal of Product Innovation Management, Vol. 5, pp. 201-215. https://doi.org/10.1111/1540-5885.5302011

Chaochotechuang, P., Daneshgar, F. and Sindakis, S. (2015), "Innovation strategies of New Product Development (NPD)", International Journal of Knowledge and Systems Science, Vol. 6 No. 2, pp.57-75. http://dx.doi.org/10.4018/ijkss.2015040104.

Chiu, M.-C. and Chu, C.-H. (2012), "Review of sustainable product design from life cycle perspectives", Int. J. Precis. Eng. Manuf., Vol. 13, pp. 1259-1272 https://doi.org/10.1007/s12541-012-0169-1

Colfer, L. J. and Baldwin, C.Y. (2016), “The mirroring hypothesis: theory, evidence, and exceptions", Ind. Corp. Chang., Vol. 25, pp. 709-738.

Conway, M.E. (1968), "How do committees invent", Datamation, Vol. 14, pp. 28-31.

Cooper, R. (1988), “The new product process: a decision guide for management”, J. Mark. Manag., Vol. 3, pp. 238-255.

Cooper, R.G. (2011), "Winning at new products: Creating value through innovation”, Basic Books.

Crawley, E., Cameron, B. and Selva, D. (2015), Systems Architecture: Strategy and Product Development for Complex Systems. Prentice Hall Press.

Dougherty, D. and Cohen, M. (1995), "Product Innovation in Mature Firms", in Bowman, E. and Kogut, B. (eds), Redesigning the Firm. Oxford University Press, New York.

Eckert, C. M., Stacey, M., Wyatt, D. and Garthwaite, P. (2012), "Change as little as possible: creativity in design by modification”, Journal of Engineering Design, Vol. 23 No. 4, pp. 337-360, http://dx.doi.org/10.1080/09544828.2011.639299.

European Union (2014), "The role of public support in the commercialisation of innovations", Eurobarometer, Vol. 394, http://dx.doi.org/10.2769/128, Available at http://ec.europa.eu/commfrontoffice/publicopinion/flash/f1_394_en.pdf

European Environment Agency - EEA (2017), "Circular by design - products in the circular economy”, EEA report No 6/2017, ISBN 978-92-9213-857-8 http://dx.doi.org/10.2800/860754.

Garcia, R. and Calantone, R. (2002), "A critical look at technological innovation typology and innovativeness terminology: a literature review”, J. Prod. Innov. Manag., Vol. 19, pp. 110-132. https://doi.org/10.1111/1540-5885.1920110

Goedhuys, M. and Veugelers, R. (2012), "Innovation strategies, process and product innovations and growth: Firm-level evidence from Brazil”, Structural Change and Economic Dynamics, Vol. 23, pp. 516-529

Hansen, M.T. and Birkinshaw, J. (2007), “The innovation value chain: a logic for fixing your company's innovation problems", Harvard Business Review, Vol. 85, pp. 121-130.

Hein, A. (2016), "Heritage technologies in space programs - assessment methodology and statistical analysis", $\mathrm{PhD}$ thesis, Technical University of Munich. Available at https://www.academia.edu/attachments/52701197/download_file?st=MTU1NDYzNjI4OCw4MC4yMTcu MTkxLjEyNg\%3D\%3D\&s=swp-splash-header

Hein, A.M., Chazall, Y., Jankovic, M. and Boutin, S. (2018), “A methodology for architecting collaborative product service system of systems", in: IEEE-13th System of Systems Engineering Conference. https://doi.org/10.1109/sysose.2018.8428697

Henderson, R. and Clark, K. (1990), “Architectural innovation: The reconfiguration of existing product technologies and the failure of established firms", Adm. Sci. Q., Vol. 35, pp. 9-30. https://doi.org/10.2307/2393549

Kaiserfledt, T. (2006), Review of Theories of Invention and Innovation (No. 47). Royal Institute of Technology, CESIS-Centre of Excellence for Science and Innovation Studies.

MacCormack, A., Rusnak, J. and Baldwin, C.Y. (2011), "Exploring the duality between product and organizational architectures: a test of the mirroring hypothesis", SSRN Electronic Journal. https://doi.org/10.2139/ssrn.1104745 
Mankins, J.C. (1995), Technology Readiness Levels-A White Paper. Advanced Concepts Office, Office of Space Access and Technology, National Aeronautics and Space Administration (NASA), Washington, DC, USA.

OECD (1991), The nature of innovation and the evolution of the productive system. technology and productivity-the challenge for economic policy.

Pahl, G., Beitz, W., Feldhusen, J. and Grote, K.-H. (2007), Engineering Design: A Systematic Approach, 3rd ed. Springer London, London. https://doi.org/10.1007/978-1-84628-319-2

Papalambros, P.Y. (2008), “Design Innovation”, J. Mech. Des., Vol. 130, p. 040201. https://doi.org/10.1115/1.2897922

Phaal, R., Farrukh, C.J.P. and Probert, D.R. (2004), “Customizing roadmapping”, Research-Technology Management, Vol. 47 No. 2, pp. 26-37. http://dx.doi.org/10.1080/08956308.2004.11671616

Schumpeter, J. (1927), “The Explanation of the Business Cycle”, Economica, Vol. 21, p. 286. https://doi.org/10.2307/2548401

Schumpeter, J.A. (1947), "The Creative Response in Economic History”, J. Econ. Hist., Vol. 7, pp. $149-159$. https://doi.org/10.1017/S0022050700054279

Schilling, M.A. (2017), Strategic Management of Technological Innovation. (5th edition.) McGraw-Hill, New York. ISBN 978-1-259-25552-6

Schulte, J. and Hallstedt, S. (2017), "Challenges and preconditions to build capabilities for sustainable product design”, In: Proceedings of the 21 st International Conference on Engineering Design (ICED 17) Vancouver, Canada, 21-25 August, Vol. 1.

Schulte, J. and Hallstedt, S.I. (2018), "Company risk management in light of the sustainability transition", Sustainability, Vol. 10, p. 4137. https://doi.org/10.3390/su10114137

Smaling, R. and de Weck, O. (2007), “Assessing risks and opportunities of technology infusion in system design”, Syst. Eng., Vol. 10, pp. 1-25. https://doi.org/10.1002/sys.20061

Sosa, M., Eppinger, S. and Rowles, C. (2004), "The misalignment of product architecture and organizational structure in complex product development”, Manage. Sci., Vol. 50, pp. 1674-1689. https://doi.org/10.1287/mnsc.1040.0289

Sosa, M., Mihm, J. and Browning, T. (2011), "Degree distribution and quality in complex engineered systems", J. Mech. Des., Vol. 133, p. 101008. https://doi.org/10.1115/1.4004973

Suh, E., Furst, M., Mihalyov, K. and de Weck, O. (2010), “Technology infusion for complex systems: A framework and case study", Syst. Eng., Vol. 13, pp. 186-203. https://doi.org/10.1002/sys.20142

Terwiesch, C. and Ulrich, K. (2009), Innovation Tournaments: Creating and Selecting Exceptional Opportunities. Harvard Business Review Press. ISBN: 9781422152225

Tushman, M. and Anderson, P. (1986), "Technological discontinuities and organizational environments", Adm. Sci. Q., Vol. 31, pp. 439-465. https://doi.org/10.2307/2392832

Utterback, J. and Abernathy, W. (1975), “A dynamic model of process and product innovation”, Omega, Vol. 3, pp. 639-656. https://doi.org/10.1016/0305-0483(75)90068-7

Willard, B. (2012), The New Sustainability Advantage: Seven Business Case Benefits of a Triple Bottom Line; New Society Publishers, Gabriola Island, BC, Canada. ISBN 0-86571-451-7

Wyatt, D.F., Eckert, C.M. and Clarkson, P.J. (2009), "Design of product architectures in incrementally developed complex products”, In DS 58-4: Proceedings of ICED 09, the 17th International Conference on Engineering Design, Vol. 4, Product and Systems Design, Palo Alto, CA, USA, 24.-27.08. 2009 (pp. 167178).

Zelkowitz, M.V. (1996), "Software engineering technology infusion within NASA", IEEE Transactions on Engineering Management, Vol. 43 No. 3, pp. 250-261. http://dx.doi.org/10.1109/17.511836

\section{ACKNOWLEDGMENTS}

Authors acknowledge participants that participated in the MMEP workshops. 